\title{
Aus dem Leben der Bienen
}

Von

\author{
Dr. K.v. Frisch
}

Professor der Zoologie und Direktor

des Zoologischen Instituts an der Universität Graz

\author{
Vierte
}

neubearbeitete und ergänzte Auflage

16. bis 20 . Tausend

Mit 112 Abbildungen

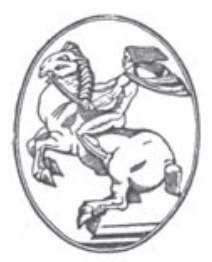

Springer-Verlag Wien GmbH 
ISBN 978-3-7091-3603-4 ISBN 978-3-7091-3602-7 (eBook)

DOI 10.1007/978-3-7091-3602-7

Alle Rechte, insbesondere das der Ubersetzung in fremde Sprachen, vorbehalten.

Copyright 1948 by Springer-Verlag Wien

Ursprünglich erschienen bei Springer-Verlag in Vienna 1948 


\section{Vorwort zur 1. Auflage}

Wenn die Naturforschung allzu scharfe Gläser aufsetzt, um einfache Dinge zu ergründen, dann kann es ihr passieren, daß sie vor lauter Apparaten die Natur nicht mehr sieht. So ist es vor nun bald zwanzig Jahren einem hochverdienten Gelehrten ergangen, als er in seinem Laboratorium den Farbensinn der Tiere studierte und zu der felsenfesten und scheinbar wohlbegründeten Überzeugung kam, die Bienen wären farbenblind. Dies gab mir den ersten Anlaß, mich näher mit ihrem Leben zu beschäftigen. Denn wer die Beziehungen der Bienen zu den farbenprächtigen Blumen aus der Beobachtung im Freien kennt, der mochte eher an einen Trugschluß des Naturforschers als an einen Widersinn der Natur glauben. Seither hat mich das Bienenvolk immer wieder zu sich zurückgezogen und immer von neuem gefesselt. Ihm verdanke ich, freilich sparsam gesäet zwischen Tagen und Wochen des Verzagens und vergeblichen Bemühens, Stunden reinster Entdeckerfreude. Der Wunsch, an selbst erlebter Freude andere teilnehmen zu lassen, war ein Beweggrund zu diesem Büchlein. In ihm werden Beobachtungen anderer Forscher und früherer Generationen, Entdeckungen meiner Mitarbeiter und eigene Befunde brüderlich beisammenstehen, ohne daß Namen genannt sind. Es soll uns nur die Sache interessieren und nicht der Entdecker.

Aber gibt es nicht Bienenbücher mehr als genng? Da ist das berühmte Werk von Maeterlinck: „Das Leben der Bienen“", oder von Bonsels: „Die Biene Maja" - beide voll vortrefflicher Naturbeobachtung, und für den Kundigen ein Genuß; aber der unkundige Leser wird schwer die Grenze finden, wo die Beobachtung aufhört und die dichterische Phantasie beginnt. Wer aus dem Leben der Bienen selbst Erbauung sucht, und nicht aus dem, was schöpferische Dichtergabe hineingelegt hat, mag sich an die Lehr- oder Handbücher der Bienenkunde wenden. Aber diese sind vor allem für den praktischen 
Imker geschrieben und darum mit mancherlei Auseinandersetzungen beschwert, die dem Naturfreund an sich fern liegen; und auch sie sind, wenn auch frei vom Genius des Dichters, oft nicht frei von Phantasie. Es bleiben noch die Werke der Wissenschaft.

Ich möchte dem Leser das Interessante aus dem Leben der Bienen übermitteln ohne den Ballast von praktischen Ratschlägen, wie ihn ein Handbuch bringen muß, ohne den Ballast eines lehrbuchmäßigen Strebens nach Vollständigkeit, ohne Beschwerung mit Zahlenmaterial, Protokollen und Belegen, mit denen eine wissenschaftliche Arbeit gewappnet sein muß, um überzeugen zu können, aber auch ohne jeden Versuch, die Poesie der Wirklichkeit phantastisch auszuschmücken.

Brunnwinkl, Ostern 1927.

K. v. Frisch.

\section{Vorwort zur 4. Auflage}

Seit dieses Büchlein als Band 1 der Sammlung „Verständliche Wissenschaft" im Verlag von Julius Springer, Berlin, erschienen ist, hat sich vieles geändert. Unser Wissen vom Bienenvolk ist um einiges reicher geworden, und so war im Text manches zu berichtigen und zu ergänzen. In anderer Hinsicht sind wir arm geworden. Als eine Folge der allgemeinen Not konnte das Bändchen, dessen 3. Auflage seit mehreren Jahren vergriffen ist, in Deutschland noch nicht wieder erscheinen. Um so mehr bin ich Herrn Otto Lange, Inhaber des Springer-Verlages in Wien, für seine Bereitwilligkeit und Herrn Dr. Ferdinand Springer, Heidelberg, für seine Zustimmung zu dieser österreichischen Ausgabe zu Dank verpflichtet.

Der Sinn des Buches wandelt sich nicht durch den Ernst der Zeit. Ein tieferes Verständnis für das Leben der Bienen wird einem offenen Gemüt allezeit eine Quelle der Erbauung bleiben und für den Imker eine Grundlage des Erfolges.

Brunnwinkl, im Februar 1948.

K. v. Frisch. 


\section{Inhaltsverzeichnis}

Seite

1. Das Bienenvolk ......................... 1

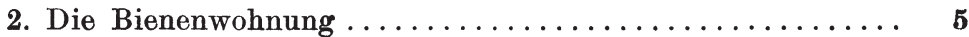

3. Die Ernährung des Bienenvolkes.................. 13

Was der Honig ist und wie ihn die Bienen sammeln 15. Der Blütenstaub und die „Höschen“ der Bienen 18. Was die Blumen gewinnen, wenn sie von den Bienen geplündert werden 22.

4. Die Bienenbrut ...................... 25

5. Der Bienenschwarm ...................... 36

6. Die Drohnenschlacht ....................... 40

7. Die Arbeitsteilung im Bienenstaate .............. 41

Der erste Lebensabschnitt 46. Der zweite Lebensabschnitt 48. Der dritte Lebensabschnitt 50. Das Alter der Bienen 50. Eingriff in die Lebensordnung - ein Störungsversuch ohne Erfolg 51.

8. Die Augen der Bienen.................... 54

Farbensehen 55. Bienenauge und Blumenfarben 60. Vom Bau der Augen 64. Sehschärfe und Formensehen der Bienen 71.

9. Der Geruchs- und Geschmackssinn.............. 75

Duftdressuren 76. Wo haben die Bienen ihre Nase? 81. Vom Riechen und Schmecken 88. Über den Geschmack läßt sich nicht streiten 91. Eine praktische Nutzanwendung 94.

10. Das Orientierungsvermögen $\ldots \ldots \ldots \ldots \ldots \ldots \ldots \ldots .96$

Die Bedeutung von Farbe und Duft als Wegweiser für die heimkehrenden Bienen 99. Der Bienenkompals 106. Der Lernvorgang und der Orientierungsflug 108.

11. Wie die Bienen miteinander reden

Ein Rundtanz als Verständigungsmittel 112. Die biologische Bedeutung des Blütenduftes, von einer neuen Seite betrachtet 117. Wie die Bienen den Blütenduft nach Hause bringen 121. Die Regelung zwischen Angebot und Nachfrage 124. 
Eine Probe mit unerwartetem Ausgang 127. Das Wunder des Schwänzeltanzes 130. Die Tänze der Pollensammler 136. Bienen tanzen im Dienste der Imkerei und Landwirtschaft 139.

12. Das Zeitgedächtnis der Bienen ................. 141

13. Die geistigen Fähigkeiten der Bienen ............. 152

14. Feinde und Krankheiten der Bienen ............. 156

15. Andere Insektenstaaten .................. 166 Der Ameisenstaat 167. Der Wespenstaat 174. Der Hummelstaat 178.

16. Von Einsiedlerbienen und von der Entstehung des Bienenstaates $\ldots \ldots \ldots \ldots \ldots \ldots \ldots \ldots \ldots \ldots \ldots . \ldots \ldots$

Sachverzeichnis ........................... 192 